\title{
Xia-Gibbs syndrome in adulthood: a case report with insight into the natural history of the condition
}

\author{
David R. Murdock, ${ }^{1,2}$ Yunyun Jiang, ${ }^{1,2}$ Michael Wangler, ${ }^{2,3}$ Michael M. Khayat, ${ }^{1,2}$ \\ Aniko Sabo, ${ }^{1,2}$ Jane Juusola, ${ }^{4}$ Kirsty McWalter, ${ }^{4}$ Krista Sondergaard Schatz, ${ }^{5}$ \\ Meral Gunay-Aygun, ${ }^{5}$ and Richard A. Gibbs ${ }^{1,2}$

\begin{abstract}
${ }^{1}$ Human Genome Sequencing Center, ${ }^{2}$ Department of Molecular and Human Genetics, Baylor College of Medicine, Houston, Texas 77030, USA; ${ }^{3}$ Texas Children's Hospital, Houston, Texas 77030, USA; ${ }^{4}$ GeneDx, Gaithersburg, Maryland 20877, USA; ${ }^{5}$ Johns Hopkins University School of Medicine, Department of Pediatrics, Institute of Genetic Medicine, Baltimore, Maryland 21287, USA
\end{abstract}

Abstract A 55-yr-old male with severe intellectual disability, behavioral problems, kyphoscoliosis, and dysmorphic features was referred for a genetic evaluation. Chromosomal microarray, RASopathy gene panel, mitochondrial sequencing, and fragile $X$ testing were all negative. Subsequent whole-exome sequencing revealed a heterozygous, truncating variant in the AHDC1 gene, consistent with a diagnosis of Xia-Gibbs syndrome (XGS). Review of his clinical history showed many classic dysmorphic and clinical features of XGS, but no major health issues in adulthood other than intellectual disability. This individual is the oldest published XGS case to date, demonstrates the wide phenotypic spectrum of the disorder, and provides information on the condition's natural history. As more adults undergo genomic studies, we will continue to learn about the adult phenotypes of genetic conditions typically diagnosed in the pediatric setting.

Corresponding author: agibbs@bcm.edu

(C) 2019 Murdock et al. This article is distributed under the terms of the Creative Commons Attribution-NonCommercial License, which permits reuse and redistribution, except for commercial purposes, provided that the original author and source are credited.

Ontology terms: intellectual disability, severe; severe global developmental delay

Published by Cold Spring Harbor Laboratory Press

doi:10.1101/mcs.a003608

\section{INTRODUCTION}

De novo truncating variants in the AT-hook DNA-binding motif-containing 1 (AHDC1) gene cause autosomal dominant Xia-Gibbs syndrome (XGS: MIM 615829) (Xia et al. 2014). XGS is a multisystemic disorder characterized by significant intellectual disability. Affected individuals may also have hypotonia, dysmorphic features, seizures, and brain anomalies among other findings (Yang et al. 2015). Approximately 100 patients worldwide have been identified with XGS, nearly all of them in the pediatric age range and the oldest being $29 \mathrm{yr}$ of age (García-Acero and Acosta 2017; Popp et al. 2017; Jiang et al. 2018; Ritter et al. 2018). To date, genomic scale sequencing has been widely adopted in the pediatric setting, where it has demonstrated a diagnostic rate of 25\% (Yang et al. 2014). Despite examples of its benefit in older patients, it remains underutilized as a diagnostic tool in adults (Posey et al. 2016). Here we describe the use of whole-exome sequencing (WES) to diagnose an adult male with intellectual disability and further define the natural history of XGS.

\section{RESULTS}

Clinical Presentation and Family History

The major clinical features of this individual are listed in Table 1. Prenatal and early-childhood information is unavailable for the individual, except that he failed to meet developmental 
Table 1. Clinical features of this individual compared to previously described Xia-Gibbs syndrome (XGS) cases

\begin{tabular}{ll}
\hline XGS features & \multicolumn{1}{c}{ Present in this case } \\
\hline Common & Noted at 6 mo of age \\
$\begin{array}{l}\text { Developmental delay } \\
\text { Speech delay }\end{array}$ & First words at age $2 \mathrm{yr}$, short sentences at $5 \mathrm{yr}$ \\
Intellectual disability & Severe (IQ 30-40) \\
Motor abnormalities & Ataxic gait, poor balance \\
Dysmorphic features & Macrocephaly, prominent forehead, large ears \\
Growth deficiencies & Short stature \\
Abnormal brain imaging & Mild atrophy \\
Hypotonia & - \\
Airway obstruction & - \\
Rare & \\
Spine anomalies & Kyphoscoliosis \\
Seizure history & Yes, but none in last 15 yr (off medication) \\
Behavioral issues & Impulse control, aggression, anxiety \\
Connective tissue abnormality & Soft, loose skin \\
Vision/hearing impairment & - \\
Craniosynostosis & - \\
Joint laxity & - \\
Notable unique features & \\
Neoplasms & \\
Hypertension & Thyroid mass, nerve sheath tumor, melanoma \\
\hline
\end{tabular}

Common and rare features of XGS were seen in $>50 \%$ and $<50 \%$ of reported cases, respectively.

milestones for walking and speech. His first words occurred around $2 \mathrm{yr}$ of age and he did not have the ability to speak in short sentences until after age $5 \mathrm{yr}$. His family describes his language issues as that of a person for whom "English is a second language, but they don't have a first language." Other than a hernia operation at 2 mo of age, there were no severe childhood illnesses or surgeries until the age of $13 \mathrm{yr}$ when he had his first grand mal seizure. He was treated with antiseizure medication (phenobarbital, ethotoin) until the age of $40 \mathrm{yr}$ and has had no recurrence since stopping treatment. Other neurological symptoms include occasional severe frontal lobe headaches and hand tremors. He has an ataxic gait with poor balance. He is able to walk independently on flat ground but requires assistance if the ground is uneven. Brain magnetic resonance imaging (MRI) at age $52 \mathrm{yr}$ was unremarkable except for generalized brain atrophy. Hearing and ophthalmologic exams have been normal.

The individual was diagnosed with kyphoscoliosis around age $10 \mathrm{yr}$ (Fig. 1). Bracing was unsuccessful and corrective surgery was discussed but not pursued. Despite imaging showing $56^{\circ}$ right thoracic scoliosis, he continues to be managed conservatively by his orthopedic surgeon with no related complications or pain. In his late 40s, he underwent resection of a nasal anterior skull base peripheral sheath tumor (detected incidentally by brain MRI) with pathology favoring a benign Schwannoma. A benign growth was removed from his thyroid at age $35 \mathrm{yr}$ and he had melanoma in situ $\times 2$ on his back. A baseline colonoscopy at age $52 \mathrm{yr}$ was normal. Other notable chronic medical issues included severe bruxism, chronic constipation, and hypertension. 


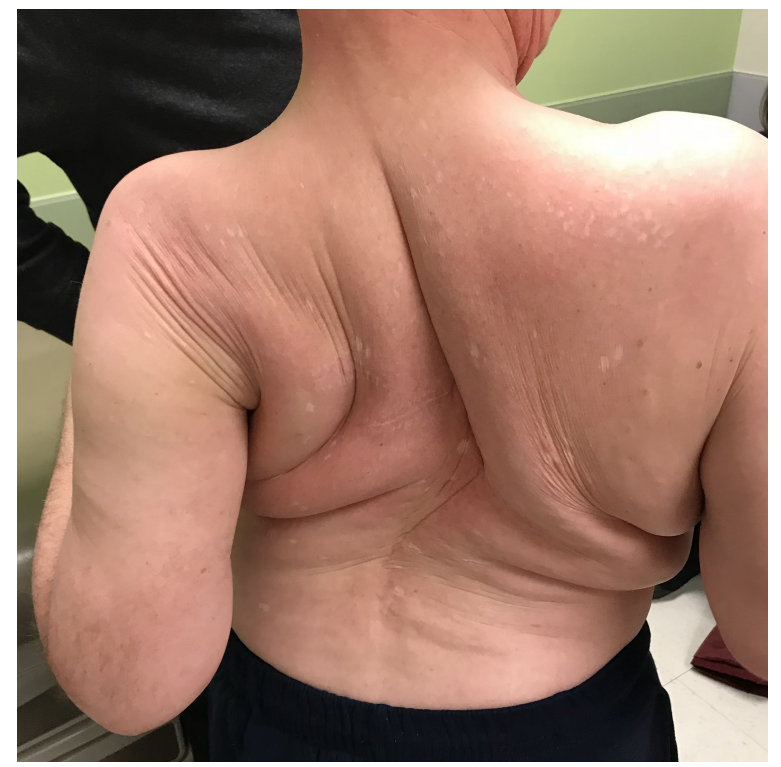

Figure 1. Photo of patient's back demonstrating the significant right thoracic kyphoscoliosis measuring $56^{\circ}$. Loose skin is also evident.

His neuropsychological history was significant for problems with impulse control, self-injurious, and aggressive behavior beginning in childhood. Such episodes are typically triggered by frustration, pain, fatigue, or unfamiliar stressful situations. He was once committed to a psychiatric hospital for extreme anxiety and violent behavior. He has had some success in reducing these episodes of anxiety with benzodiazepines. Cognitive testing as a child revealed a full-scale IQ between 30 and 40 . He has been consistently talkative and social, and his expressive language is more advanced compared to other cognitive measures. He has lived with family members or in group homes his entire life and has not been formally schooled. He understands speech but is unable to read or write. Sleep disturbances have been lifelong.

Beginning in his mid 40s, he has exhibited slowly progressive cognitive decline. He can follow simple commands but usually cannot follow complex (two-step or more) commands. $\mathrm{He}$ is able to answer binary but not open-ended questions. His speech has slowed but his overall ability and the number of words is stable. Many daily activities require assistance, including using the toilet and showering, but he is able to feed and dress himself. Urinary and fecal incontinence began in his early 50s and he now wears a diaper at all times.

The individual is the third child of his parents who had an additional pregnancy that ended in a spontaneous miscarriage. Parents were of Irish ancestry without any known consanguinity. He has two generally healthy older siblings, although the brother's history is significant for obesity, a desmoid tumor, and macular degeneration and the sister has a history of obesity, macular degeneration, and a basal cell carcinoma. The remainder of the family history was negative for congenital anomalies, intellectual disability, multiple miscarriages/stillbirths, or known genetic diseases. The patient's mother died at age $65 \mathrm{yr}$ from metastatic lung cancer with a positive smoking history. His father died in his 70 s with a history of chronic obstructive pulmonary disease, macular degeneration, prostate and squamous cell cancers, and two abdominal aortic aneurysms in his 60s.

The individual was evaluated at a clinical genetics clinic at age 55 . On physical exam, he had short stature with a height of $1.6 \mathrm{~m}\left(5^{\prime} 3^{\prime \prime}\right)$ and a weight of $62.1 \mathrm{~kg}(136.7 \mathrm{lb})$. Dysmorphic 
C OLD SPRING HARBOR Molecular Case Studies
Xia-Gibbs syndrome in adulthood
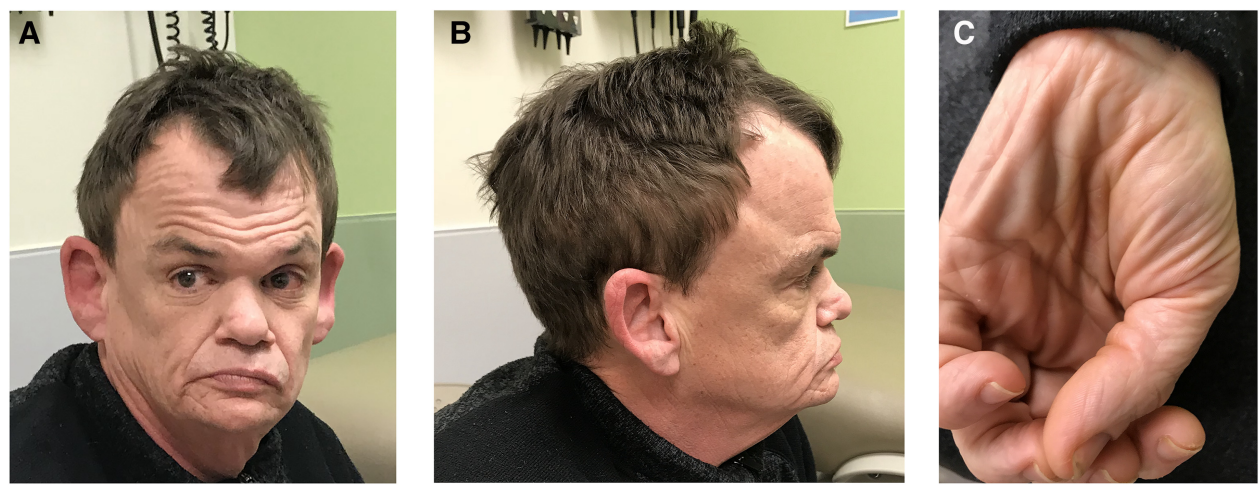

Figure 2. Front and side images of patient's head. From the front $(A)$, the macrocephaly, prominent forehead, loose skin, and wide mouth are evident. Profile view (B) shows the large, thickened ears and hypoplastic maxilla. Hand photo $(C)$ demonstrates soft, loose skin over the palmar side.

features included macrocephaly (head circumference $>99$ percentile), narrow palpebral fissures, prominent forehead, large thickened ears, wide mouth, and a hypoplastic maxilla (Fig. 2). Soft, loose skin was present on the face, neck, back, dorsal, and palmar/plantar sides of hands and feet. Significant kyphoscoliosis, reduced elbow extension, small hands and feet, and high foot arches were also noted. He had a protruding chest and widely spaced nipples. Because of the intellectual disability and dysmorphic features, a chromosomal microarray was performed. Fragile $X$ testing was also sent secondary to the history of a male with large ears, attention-deficit/hyperactivity disorder (ADHD), seizures, and intellectual disability. A Noonan spectrum and RASopathy gene panel were also sent with the phenotypic overlap with Costello syndrome. Those tests were nondiagnostic, and so clinical testing was advanced to WES with mitochondrial DNA analysis.

\section{Whole-Exome Sequencing}

Determination of the DNA sequence of the coding regions of the genomes of the individual and his unaffected brother and sister by WES revealed that he harbored a heterozygous variant in the AHDC1 gene that would be predicted to lead to protein truncation, consistent with the diagnosis of XGS. The individual's parents were deceased and unavailable to confirm de novo status. However, neither unaffected sibling harbored the variant. The observed variant [NM_001029882.2:c.979C>T (p.Gln327*)] is predicted to cause the disorder either through the presence of the truncated form of the protein (i.e., a dominant negative effect) or else through haploinsufficiency, via the absence of sufficient normal protein. The AHDC1 c.979C>T (p.Gln327*) variant was not observed in the Genome Aggregation Database (gnomAD) or ExAC databases (Lek et al. 2016) and was predicted to be damaging, by in silico algorithms (Table 2). Per ACMG criteria (Richards et al. 2015), this AHDC1 variant was classified as "likely pathogenic."

Whole-exome sequencing also revealed two variants of uncertain significance (VUSs) in the NSUN5 gene [NM_018044.4:c.349C>T (p.Arg117Trp) and c.472G >C (p.Gly158Arg)]. Segregation analysis confirmed these variants to be in trans as each unaffected sibling carried one of the alleles. The contribution of the NSUN5 variants to the individual's phenotype is unknown at this time, because this gene has no current disease association. Mitochondrial genome sequencing identified a homoplasmic VUS in the MT-TH gene (NC_012920.1: $\mathrm{m} .12191 \mathrm{C}>\mathrm{T}$ ) in the individual. Targeted testing in an unaffected maternal aunt showed the same homoplasmic variant, suggesting that it was most likely noncontributory to the individual's phenotype. 


\begin{tabular}{|c|c|c|c|c|c|c|c|}
\hline Gene & $\begin{array}{l}\text { Genomic location } \\
\text { (GRCh37) }\end{array}$ & Nucleotide change & $\begin{array}{l}\text { Amino acid } \\
\text { change }\end{array}$ & Zygosity & $\begin{array}{l}\text { CADD } \\
\text { Phred }\end{array}$ & $\begin{array}{l}\text { Max } \\
\text { allele } \\
\text { freq }^{a}\end{array}$ & $\begin{array}{c}\text { ACMG } \\
\text { interpretation }\end{array}$ \\
\hline$A H D C 1$ & Chr 1:27877648G >A & NM_001029882.2:c.979C > T & p.Gln327* & Heterozygous & 37 & 0 & Likely pathogenic \\
\hline NSUN5 & Chr 7:72721622G >A & NM_018044.4:c.349C > T & p.Arg117Trp & Heterozygous & 25.2 & 0.0022 & VUS \\
\hline NSUN5 & Chr 7:72721419C > G & NM_018044.4:c.472G >C & p.Gly158Arg & Heterozygous & 26.6 & 0.00047 & VUS \\
\hline MT-TH & & NC_012920.1:m.12191C > T & & Homoplasmic & & & VUS \\
\hline
\end{tabular}

(VUS) Variant of uncertain significance; $\left({ }^{*}\right)$ gnomAD frequency.

\section{DISCUSSION}

At age $55 \mathrm{yr}$ at the time of diagnosis, this individual is the oldest known case of XGS, an autosomal dominant disorder caused by de novo truncating variants in the AHDC1 gene (Xia et al. 2014). XGS has traditionally been diagnosed in the pediatric setting, with the majority of cases less than $10 \mathrm{yr}$ of age at diagnosis and the oldest being $29 \mathrm{yr}$ old (García-Acero and Acosta 2017; Jiang et al. 2018; Ritter et al. 2018). Affected individuals commonly have hypotonia, intellectual disability, dysmorphic features, and brain anomalies, but the phenotype can be variable. The patient described here shares many of those features, including the dysmorphisms, intellectual disability, and brain atrophy. There are notable differences, however, that may be important in the management of aging patients with XGS and may provide insight into the natural history of the disorder. The common, rare, and unique features in this case compared to those previously described are summarized in Table 1.

One notable difference in this case is the absence of hypotonia, a finding in $90 \%$ of previously described cases (Jiang et al. 2018). This individual's tone was normal, and he was actually quite strong on exam. Nevertheless, he has significant coordination difficulties with an ataxic gate and poor balance. Sleep apnea is another common finding with XGS that was not seen here despite the presence of general sleep disruption. Craniosynostosis has been reported in 3/19 (15.8\%) XGS cases recently described (Ritter et al. 2018) but was not noted on this individual's exam or imaging. Interestingly, this individual had significant macrocephaly (head circumference $>99$ percentile), a finding that can occasionally be seen with Muenke syndrome, an FGFR3-related craniosynostosis condition (Kruszka et al. 1993). At this time, however, it is unclear what role, if any, AHDC1 mutations play in this condition of premature cranial suture closure (Miller et al. 2017).

The patient's unique history of a benign thyroid mass, nerve sheath tumor (benign Schwannoma), and melanoma is notable and suggests a possible increased risk for malignancy. The function of $A H D C 1$ is not well understood but it shares a domain with REV $3 L$, a gene implicated in DNA translesion repair (Fig. 3; Gan et al. 2008). Inherited defects in DNA repair mechanisms are known to carry a higher cancer risk, for example skin cancer in xeroderma pigmentosa (Gan et al. 2008). Until we better understand the complete function of $A H D C 1$, it is important for patients with XGS to receive age-appropriate cancer screening (colonoscopy, mammogram, etc.) and to have a low threshold for specialist referral if indicated. Similarly, as individuals with XGS progress into adulthood, they should receive proper screening and management of conditions like hypertension, as was done in this case.

One striking finding on physical exam was the individual's significant kyphoscoliosis, measuring $56^{\circ}$ in the thoracic spine $\left(>40^{\circ}\right.$ is considered severe) (Fig. 1). We recently 


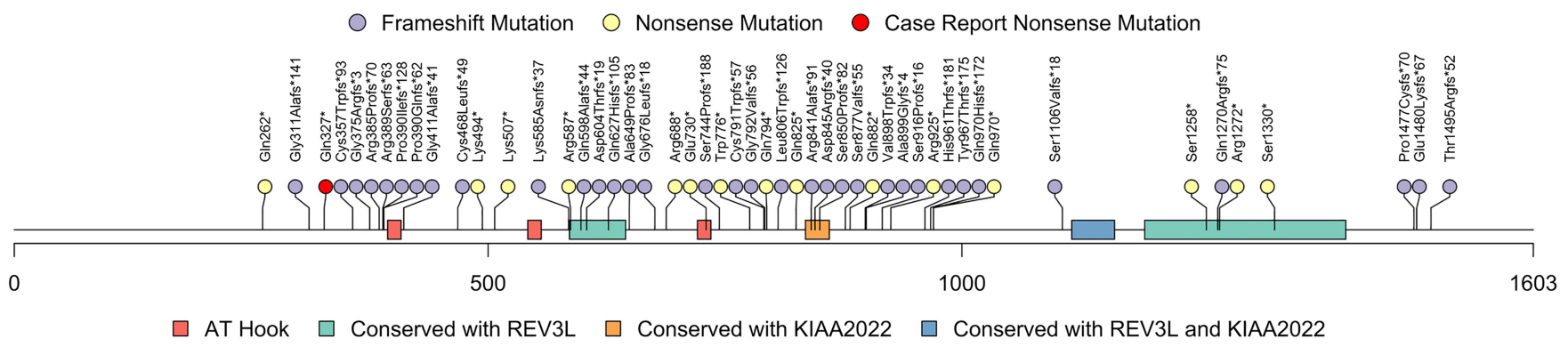

Figure 3. Graphical depiction of the known XGS-associated AHDC1 variants. Amino acid positions are on the $x$-axis with purple and yellow circles representing frameshift and nonsense mutations, respectively. This individual's p.Gln327* mutation is indicated by the red circle. Rectangles represent different protein domains, including AT-hook domains in pink, REV3L homology domains in green, KIAA2022 homology domains in orange, and both REV3L and KIAA2022 homology domains in blue.

reported scoliosis in $20 \%$ of surveyed individuals with XGS, which is a significant increase compared to a general prevalence of $5 \%$ (Jiang et al. 2018). Scoliosis occurs in connective tissue disorders, like Marfan syndrome, because of bone overgrowth and ligamentous laxity (Dietz 1993). It is also common in neuromuscular conditions, including Duchenne muscular dystrophy, Friedreich ataxia, and cerebral palsy. In these neurologic conditions, the hypothesized etiology is disorganized control of trunk muscles leading to progressive spinal imbalance and eventually to scoliosis (Vialle et al. 2013). It is likely that scoliosis in XGS is due to a similar process as a result of neurologic deficits. However, a connective tissue component cannot be excluded given that this individual also had soft, loose skin. Furthermore, a recent cohort study described connective tissue abnormalities, including the skin, in 9/19 (47\%) cases (Ritter et al. 2018). Regardless of the etiology, early recognition of scoliosis in XGS permits interventions to prevent complications like life-threatening cardio-respiratory compromise.

Another notable finding in this adult with XGS is his neuropsychiatric history. Behavioral issues were first observed in some XGS patients (Yang et al. 2015), and a more recent description of additional individuals noted instances of problems with impulse control, selfinjurious and aggressive behavior, inappropriate social responses, and marked problems with sleep (Jiang et al. 2018). This adult had some of these behaviors that have required care of medical professionals and pharmacologic intervention. It should be noted that these features are variable in XGS patients and many are not aggressive in any way. As in all neurodevelopmental conditions, such behaviors can have profound negative impact on patient and family quality of life, jeopardizing educational opportunities or leading to residential placement, for example (McGuire et al. 2016). Thus, it is crucial to refer patients with XGS early to the appropriate specialists if they exhibit behavioral or mental health issues.

The mechanism of pathogenesis for AHDC1 mutations remains unresolved. All XGS-associated mutations described to date are presumed de novo truncating variants, possibly acting through a dominant negative mechanism (Xia et al. 2014). One recently published case (Park et al. 2017) and others in the DECIPHER database (Firth et al. 2009) with developmental delay and deletions of AHDC1 and other genes suggest haploinsufficiency should also be considered as a disease mechanism. It has also been suggested that patients with early mutations in AHDC1 may have milder phenotypes and slightly higher measures of cognitive ability than those with more distal mutations (Jiang et al. 2018). However, there is significant variability, even among individuals with the same mutation, making it difficult to draw any conclusions. The frameshift mutation described here is located very early in the 
gene, toward the amino terminus of the encoded protein (p.Gln327*), which could suggest a milder predicted phenotype. However, though the patient is generally healthy, he has severe intellectual disability with an $1 \mathrm{O}$ of 30-40. In contrast, a 29-yr-old male with XGS and a very distal mutation (p.Cys1499Valfs*9) was recently described as having only moderate intellectual disability, is trilingual, and employed (Ritter et al. 2018). Thus, a larger number of cases and a better understanding of the disease mechanism is needed to elucidate any true genotype-phenotype correlations.

Until recently, XGS has largely been considered a disorder of childhood. Of the $>100$ XGS cases described to date, the three oldest are only in their 20s (Jiang et al. 2018; Ritter et al. 2018), demonstrating that our understanding of the natural history of XGS is limited. Genetic diseases are often well described in the pediatric age range because that is when they are typically diagnosed. In a recent study describing data from 2000 WES cases performed in a clinical setting, only $12 \%$ were adult patients (Yang et al. 2014). The adult phenotype may not be well defined or may be unfamiliar to the adult physician. For example, a recent study of screening copy number variation in adults demonstrated that only one in 12 adults had been correctly diagnosed with the 22q11.2 deletion syndrome though 10 of 12 had clinical features consistent with the diagnosis (e.g., congenital heart defect, neurodevelopmental disorder) (Maxwell et al. 2017). Phenotypic expression may also be subtler in adulthood, because of mosaicism or variable expressivity. As a consequence, WES may currently be underutilized in adults with intellectual disability in whom phenotypes are less defined. Nevertheless, the diagnostic utility of WES in adults has been demonstrated, for example in one study in which a molecular diagnosis was made in $17.5 \%$ of adults undergoing WES, rising to $27.7 \%$ in those with neurodevelopmental abnormalities like this case (Posey et al. 2016). It may also suggest that AHDC1 might be implicated in some fraction of institutionalized adults that have never undergone a genetic evaluation.

In conclusion, this case represents the oldest individual diagnosed with XGS to date. Overall, he remains healthy well into his 50 s, suggesting that life span may not be dramatically altered in XGS. With continued support and interventions, such individuals may continue to thrive into adulthood. This report suggests that XGS should be considered in the differential diagnosis of adults with unexplained intellectual disability and dysmorphic features. Last, it demonstrates the need to generally consider classically defined pediatric conditions in adults.

\section{METHODS}

\section{Whole-Exome Sequencing}

Using genomic DNA from the submitted specimens, the exonic regions and flanking splice junctions of the genome were captured and sequenced at GeneDx on an Illumina system with 150-bp paired-end reads. Reads were aligned to human genome build GRCh37/ UCSC hg19 and then analyzed for sequence variants. Potentially pathogenic variants were confirmed with Sanger sequencing. Mean depth of coverage was $123 \times$, and $98.7 \%$ of the targeted region was sequenced to a coverage of at least $10 \times$ (Table 3 ).

\begin{tabular}{ll}
\hline Table 3. Whole-exome sequencing metrics & \\
\hline Mean depth of coverage & $123 \times$ \\
Percentage of exome with at least $10 \times$ coverage & $98.70 \%$ \\
Percentage of $A H D C 1$ coding region with at least 10x coverage & $100 \%$ \\
\hline
\end{tabular}


Competing Interest Statement

Jane Juusola and Kirsty McWalter are employees of GeneDx.

Received October 17, 2018 accepted in revised form January 3, 2019

\section{ADDITIONAL INFORMATION}

\section{Data Deposition and Access}

The confirmed genetic variant was deposited to ClinVar (https://www.ncbi.nlm.nih.gov/ clinvar/) under accession number SCV000618821. Whole-exome sequencing data are not publicly available because consent could not be obtained.

\section{Ethics Statement}

Written consent for the case report and pictures was obtained from the individual's guardian. The study was approved by the Institutional Review Board of Baylor College of Medicine.

\section{Acknowledgments}

We thank the subject of this case report and his family for their generous contributions.

\section{Author Contributions}

All authors were involved in the study design, manuscript preparation, and data analysis, as well as reviewing, of the final manuscript.

\section{Funding}

This work was supported by the Baylor-Hopkins Center for Mendelian Genomics (HG006542) and by a private donation. R.A.G. was also supported as a visiting scholar of the Texas Institute for Advanced Studies.

\section{REFERENCES}

Dietz H. 1993. Marfan syndrome. University of Washington, Seattle.

Firth HV, Richards SM, Bevan AP, Clayton S, Corpas M, Rajan D, Van Vooren S, Moreau Y, Pettett RM, Carter NP. 2009. DECIPHER: database of chromosomal imbalance and phenotype in humans using ensembl resources. Am J Hum Genet 84: 524-533. doi:10.1016/j.ajhg.2009.03.010

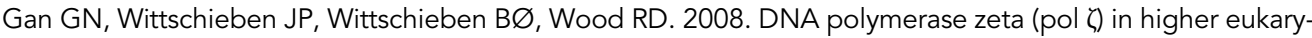
otes. Cell Res 18: 174-183. doi:10.1038/cr.2007.117

García-Acero M, Acosta J. 2017. Whole-exome sequencing identifies a de novo AHDC1 mutation in a Colombian patient with Xia-Gibbs syndrome. Mol Syndromol 8: 308-312. doi:10.1159/000479357

Jiang Y, Wangler MF, McGuire AL, Lupski JR, Posey JE, Khayat MM, Murdock DR, Sanchez-Pulido L, Ponting CP, Xia F, et al. 2018. The phenotypic spectrum of Xia-Gibbs syndrome. Am J Med Genet Part A 176: 1315-1326. doi:10.1002/ajmg.a.38699

Kruszka P, Addissie YA, Agochukwu NB, Doherty ES, Muenke M. 1993. Muenke syndrome. In GeneReviews ${ }^{\circledR}$ (Internet) (ed. Adam MP, Ardinger HH, Pagon RA, Wallace SE, Bean LJH, Stephens K, Amemiya A). University of Washington, Seattle, WA.

Lek M, Karczewski KJ, Minikel EV, Samocha KE, Banks E, Fennell T, O'Donnell-Luria AH, Ware JS, Hill AJ, Cummings BB, et al. 2016. Analysis of protein-coding genetic variation in 60,706 humans. Nature 536: 285-291. doi:10.1038/nature19057

Maxwell EK, Packer JS, O'Dushlaine C, McCarthy SE, Hare-Harris A, Staples J, Gonzaga-Jauregui C, Fetterolf SN, Faucett WA, Leader JB, et al. 2017. Profiling copy number variation and disease associations from 50,726 DiscovEHR Study exomes. bioRxiv doi:10.1101/119461

McGuire K, Fung LK, Hagopian L, Vasa RA, Mahajan R, Bernal P, Silberman AE, Wolfe A, Coury DL, Hardan AY, et al. 2016. Irritability and problem behavior in autism spectrum disorder: a practice pathway for pediatric primary care. Pediatrics 137: S136-S148. doi:10.1542/peds.2015-2851L

Miller KA, Twigg SRF, McGowan SJ, Phipps JM, Fenwick AL, Johnson D, Wall SA, Noons P, Rees KEM, Tidey $E A$, et al. 2017. Diagnostic value of exome and whole genome sequencing in craniosynostosis. J Med Genet 54: 260-268. doi:10.1136/jmedgenet-2016-104215

Park HY, Kim M, Jang W, Jang DH. 2017. Phenotype of a patient with a 1p36.11-p35.3 interstitial deletion encompassing the AHDC1. Ann Lab Med 37: 563-565. doi:10.3343/alm.2017.37.6.563 
Popp B, Ekici AB, Thiel CT, Hoyer J, Wiesener A, Kraus C, Reis A, Zweier C. 2017. Exome Pool-Seq in neurodevelopmental disorders. Eur J Hum Genet 25: 1364-1376. doi:10.1038/s41431-017-0022-1

Posey JE, Rosenfeld JA, James RA, Bainbridge M, Niu Z, Wang X, Dhar S, Wiszniewski W, Akdemir ZHC, Gambin T, et al. 2016. Molecular diagnostic experience of whole-exome sequencing in adult patients. Genet Med 18: 678-685. doi:10.1038/gim.2015.142

Richards S, Aziz N, Bale S, Bick D, Das S, Gastier-Foster J, Grody WW, Hegde M, Lyon E, Spector E, et al. 2015. Standards and guidelines for the interpretation of sequence variants: a joint consensus recommendation of the American College of Medical Genetics and Genomics and the Association for Molecular Pathology. Genet Med 17: 405-424. doi:10.1038/gim.2015.30

Ritter AL, McDougall C, Skraban C, Medne L, Bedoukian EC, Asher SB, Balciuniene J, Campbell CD, Baker SW, Denenberg EH, et al. 2018. Variable clinical manifestations of Xia-Gibbs syndrome: findings of consecutively identified cases at a single children's hospital. Am J Med Genet Part A 176: 1890-1896. doi:10 .1002/ajmg.a.40380

Vialle R, Thévenin-Lemoine C, Mary P. 2013. Neuromuscular scoliosis. Orthop Traumatol Surg Res 99: S124S139. doi:10.1016/j.otsr.2012.11.002

Xia F, Bainbridge MN, Tan TY, Wangler MF, Scheuerle AE, Zackai EH, Harr MH, Sutton VR, Nalam RL, Zhu W, et al. 2014. De novo truncating mutations in AHDC1 in individuals with syndromic expressive language delay, hypotonia, and sleep apnea. Am J Hum Genet 94: 784-789. doi:10.1016/j.ajhg.2014.04.006

Yang Y, Muzny DM, Xia F, Niu Z, Person R, Ding Y, Ward P, Braxton A, Wang M, Buhay C, et al. 2014. Molecular findings among patients referred for clinical whole-exome sequencing. J Am Med Assoc 312: 1870-1879. doi:10.1001/jama.2014.14601

Yang H, Douglas G, Monaghan KG, Retterer K, Cho MT, Escobar LF, Tucker ME, Stoler J, Rodan LH, Stein D, et al. 2015. De novo truncating variants in the AHDC1 gene encoding the AT-hook DNA-binding motifcontaining protein 1 are associated with intellectual disability and developmental delay. Mol Case Stud 1: a000562. doi:10.1101/mcs.a000562 


\section{COLD SPRING HARBOR Molecular Case Studies}

\section{Xia-Gibbs syndrome in adulthood: a case report with insight into the natural history of the condition}

David R. Murdock, Yunyun Jiang, Michael Wangler, et al.

Cold Spring Harb Mol Case Stud 2019, 5: a003608 originally published online January 8, 2019 Access the most recent version at doi: $10.1101 / \mathrm{mcs} . a 003608$

References This article cites 17 articles, 3 of which can be accessed free at: http://molecularcasestudies.cshlp.org/content/5/3/a003608.full.html\#ref-list-1

License This article is distributed under the terms of the Creative Commons Attribution-NonCommercial License, which permits reuse and redistribution, except for commercial purposes, provided that the original author and source are credited.

Email Alerting Receive free email alerts when new articles cite this article - sign up in the box at the Service top right corner of the article or click here. 